ALPHA N 27 Diciembre 2008 (167-184)

ISSN 0716-4254

http://alpha.ulagos.cl

\title{
EL ESCRITOR SOLDADO: LA CONFIGURACIÓN DE UNA IDENTIDAD IDEAL EN LAS HISTORIAS DE LA LITERATURA COLOMBIANA
}

The Soldier Writer: Configurations of an Ideal Identity in the Stories of Colombian Literature

\author{
Diana Paola Guzmán* \\ Escribir no tiene nada que ver con \\ significar, sino con deslindar, \\ cartografiar, incluso, futuros paisajes. \\ Gilles Deleuze (1971)
}

\section{Resumen}

La figura del escritor soldado en las historias de la literatura constituye una suerte de paradigma fundacional en la construcción de la idea del intelectual latinoamericano. Dicho paradigma es objeto de una dinámica que hemos llamado el círculo de metamorfosis y evidencia un proceso que va del escritor soldado en la batalla — representado por Gonzalo Jiménez de Quesada- al prócer escritor formador de la opinión pública y narrador de la historia. Todas estas figuras van tomando parte en la construcción de la identidad nacional y en el ideal del intelectual latinoamericano vinculado a la batalla y a los actos performativos propios de la Emancipación, hipótesis que pretende dejar la puerta abierta a futuras discusiones en torno al papel de las historias de la literatura dentro del devenir social e histórico del continente.

Palabras clave: nación, intelectual, independencia, escritura, soldado, prócer.

Abstract

The figure of the soldier writer in literature stories constitutes a foundational paradigm in the construction of the idea about the Latin-American intellectual. Such paradigm is the object of a dynamic that we named the circle of metamorphosis, which evidences the process that begins with the soldier writer in battle - represented by Gonzalo Jiménez de Quesada — and ends with the hero writer as a constructer of public opinion and narrator of national history. All these images take part in the construction of national identity and in the ideal of the Latin-American intellectual linked to the battle and performance characteristics of Emancipation. Thus, this article aims to open the door for future discussions around the rol of literature stories inside the social and historical development of the continent.

Key words: nation, intellectual, independence, writer, soldier, hero. 


\section{Diana Paola Guzmán}

\section{GONZALO JIMÉNEZ DE QUESADA: EL PARADIGMA DEL ESCRITOR SOLDADO.}

A mediados del siglo XIX, un número considerable de historiadores de la literatura (Vergara y Vergara, 1867; Gómez Restrepo, 1938) fijaron sus ojos en las figuras ejemplificantes, tal como lo hicieron los seguidores de Bolívar o el argentino Mitre con San Martín. Más allá de querer fortalecer la función didáctica y aleccionadora de la escritura, los episodios del drama biográfico unificaron en una línea narrativa la dispersión de acontecimientos múltiples y heterogéneos: "La solución debía ser la amplificación desmesurada de la identidad personal, el desbordamiento del cauce biográfico y su adopción como microcosmos o como representante simbólico de una entidad colectiva" (Colmenares, 1989:60).

Para José María Vergara y Vergara, el primer historiador de la literatura colombiana, la misión del héroe, desde Gonzalo Jiménez de Quesada hasta Rafael Núñez, es la misma: configurar la nación sobre pilares sociales fuertes que debían reflejarse en la literatura constituyéndola como una base segura y autónoma: "La función de la literatura, como la función de la lengua, es, pues, en el período de la emancipación, una función de legitimación de las naciones recientes, de afirmación de la autonomía que está construyendo el Estado" (Pizarro, 1994:26).

Pero la figura del héroe se convierte en paradigma cuando su presencia abarca un gran número de obras que tienen como objetivo historiar las letras nacionales, como las de Vergara y Vergara y Gómez Restrepo. Sin embargo, la dinámica del escritor soldado dentro de las historias literarias colombianas presenta un constante movimiento, una suerte de evolución que trae consigo la función y el cambio de los imaginarios en el proceso de construcción de la tradición literaria nacional, evolución que expondremos y analizaremos según sus consecuencias en la construcción de la imagen del intelectual colombiano. En aras de proponer un orden metodológico se sugerirá un círculo de metamorfosis $^{1}$ que presenta el siguiente orden: escritor y soldado, soldado a prócer escritor y, finalmente, de prócer a intelectual, caracterizaciones

\footnotetext{
${ }^{1}$ Para Paul Ricoeur, una figura se convierte en paradigma cuando a lo largo del tiempo ha experimentado distintos procesos de "implantación” en la memoria colectiva. Dentro del relato histórico, el personaje experimenta una serie de metamorfosis en los imaginarios colectivos: innovación, estabilidad y decadencia. En el caso de la figura del escritor soldado dentro del relato histórico, su presencialidad como paradigma se evidencia en la pervivencia a lo largo del desarrollo de la historiografía literaria. Dicha permanencia trae consigo cambios que tienen como objetivo generar una imagen perdurable dentro de la conciencia nacional. Cfr. Tiempo y narración (1998).
} 
inauguradas por Vergara y Vergara y por Gómez Restrepo que permanecerán por tiempo considerable en el corpus de las historias posteriores.

Aunque para estos historiadores el inicio de las letras colombianas entronca su origen en la conquista y en la fundación de ciudades, en el caso de Vergara, el Licenciado Jiménez de Quesada representa, no sólo el origen de la empresa civilizatoria liderada por la península, sino una fracción de la España letrada que se oponía a la imagen bárbara de los primeros conquistadores ${ }^{2}$

(...) y este lenguaje, más general y más usado, más inculto e incorrecto, fue el que trajeron nuestros conquistadores y el que se habló y escribió por mucho tiempo en el Nuevo Reino, aún después de consumada en España la revolución introducida por Boscán, Garcilaso y sus imitadores (1867:28).

Para Gómez Restrepo, la figura de Quesada también conforma la representación más visible de la España civilizada dando paso a lo que sería la primera característica de la figura del escritor soldado: antes de ser un hombre de guerra, es, principalmente, un hombre de letras: "Para este país constituye una fortuna el haber sido conquistado, no por un aventurero ignorante y brutal, sino por un hombre culto y letrado" (1938:18).

De manera procesual, estos autores van construyendo el círculo de metamorfosis, destacando - en primer lugar- el alto sentido del deber que obliga a estos escritores a convertirse en guerreros empuñando la bandera de la civilización. Así, la dicotomía entre la civilización y la barbarie que tanto preocupó a los españoles americanos va siendo superada a través de la presencia del escritor soldado. Es decir, era necesario crear una base firme para consolidar una tradición que luego de la Independencia resultaba fundamental. Dicha base no podría situarse en otro punto distinto a España. En palabras de Joaquín Santana

(...) llegada a América con los “descubridores”, la problemática de la civilización-barbarie devino el instrumento ideológico por excelencia para justificar la conquista y colonización del nuevo mundo... ésta adquirió un carácter y contenido nuevo al asociarse a la modernización y a los procesos mentales de lo que pudiera denominarse contemporáneamente como estilo de pensamiento desarrollista (2005:15).

\footnotetext{
${ }^{2}$ La imagen de los primeros conquistadores como bárbaros que fueron, posteriormente reemplazados por una fracción de letrados peninsulares, es también uno de los temas principales de la obra de José María Samper (1961).
} 


\section{Diana Paola Guzmán}

El paradigma de Quesada no sólo conforma el punto de partida para generar una historia civilizada del continente donde, como lo hace notar Gómez Restrepo, se contó con la suerte de ser conquistados por un letrado y no por un bárbaro ignorante, sino que también configura la imagen ideal de ciudadano, la esencia de la nación: "Su profesión fue la de hombre de leyes; y este país ha sido profundamente legalista, enamorado de las fórmulas de la ley escrita y amigo del régimen civil en el gobierno" (1938:19). Para Vergara y Gómez Restrepo, la característica más importante de la nación que se estaba construyendo es, precisamente, su amor por las leyes y por el sistema institucional.

Por tal razón, resulta fundamental que la incursión del escritor soldado dentro de la historia de la literatura comience con una descripción biográfica que ocuparía gran parte de su presentación en el engranaje de la obra. Poco a poco se va evidenciando una historia con tono monumentalista ${ }^{3}$ que contribuye a la reafirmación de estas figuras como ideales de identidad. Ejemplo de ello es que, en un primer momento, los escritores seleccionados por las historias de la literatura colombiana son presentados desde lo que la historia social llama estructuras de lo cotidiano, es decir, propuestos desde su quehacer vital y diario, desde su labor pública y heroica. Un segundo ámbito, es el de los juegos de intercambio, los que ocupan una posición secundaria dentro del discurso narrativo. A través de la representación de sus obras, el historiador-narrador da cuenta del escenario social general en el que interviene el escritor y su obra.

Ya en el tiempo nacional es donde la obra literaria, junto con el autormonumento, entra a formar parte de procesos colectivos y políticos, en su mayoría, identitarios. En este sentido, el entramado que convierte a los escritores en sujetos históricos no se da solamente desde una narración biográfica, sino que subyace desde la relación que éstos establecen con el acontecer político y social. En especial, los autores seleccionados por Vergara y Vergara tuvieron incidencia en lo que posteriormente se constituye como la Independencia. Cada uno era presentado como un peldaño que conformaba el largo camino hacia la emancipación. En palabras de Paul Ricoeur

Una vez que pasa el tiempo, el significado de las vidas humanas reales — pueden ser vidas individuales y colectivas - se reduce al intercambio que esas vidas reciben cuando el historiador les da el aspecto de relatos

\footnotetext{
${ }^{3}$ Para Renato Rosaldo (1991) la historia monumentalista está ligada, en forma irreductible, a la presencia de un sustrato ideológico regente. Sus motivos se limitan a dar cuenta de la vida y de las obras producidas por representantes del grupo que se encuentra en el poder. Así, para Vergara y Vergara, las figuras que debían historiarse son aquéllas que participaron en la Independencia y que jamás olvidaron la relación lingüística y religiosa con España.
} 
con un comienzo, punto medio y final, apuntando hacia un objetivo común [la Independencia] (1999:115).

La forma de darles a estas figuras un espacio dentro del relato histórico se relaciona íntimamente con la creación de monumentos que merecen y deben ser recordados por la colectividad. En el caso de los juegos de intercambio, las figuras dejan de ser simples monumentos que abren paso al relato histórico y se convierten en documentos construidos por el historiador. Son analizadas por medio de su relación con el contexto y la historia general del país. A través de ellas se da cuenta de lo sucedido en el medio social y su incidencia en la literatura.

En consecuencia, resulta de vital importancia cerrar el primer círculo de metamorfosis y restituir, al ahora soldado, su investidura de escritor. Es lo que sucede con Quesada, según Gómez Restrepo: "Quesada fue militar en ocasión, como lo ha sido la mayor parte de nuestros guerreros, que, terminada la lucha armada, han vuelto a sus cargos civiles y a su amor por la letras, que nunca abandonó” (1938:19). Muestra de ello son las largas páginas que tanto Vergara y Vergara como Gómez Restrepo dedican a las discusiones que sostenía Jiménez de Quesada con los compañeros de la expedición en el Magdalena (1536) y cuyo tema central era la imposición del metro italiano sobre el metro castellano, lo que no era del gusto de Quesada.

Dichas disputas son descritas en el fragmento que Vergara y Vergara, cita de Las Elegías de Varones Ilustres de Indias de Juan de Castellanos

Jiménez de Quesada, licenciado, que es Adelantado deste Reino, de quien puedo decir no ser ayuno del poético gusto y ejercicio: y él porfió conmigo muchas veces ser los metros antiguos castellanos los propios y adaptados a su lengua por ser hijos nacidos de su vientre y éstos (los italianos) advenedizos adoptivos (1867:28-29). ${ }^{4}$

En un primer momento, es necesario aclarar que los escritores soldados presentados dentro de las historias literarias siempre son letrados que han tenido que tomar las armas por un alto sentido del deber. Ejemplo de ello es la presentación que de Francisco José de Caldas lleva a cabo Gómez Restrepo

\footnotetext{
${ }^{4}$ Es evidente que el fragmento de Castellanos elegido por Vergara no sólo tiene como objetivo demostrar la erudición de Quesada sino, también, su profundo amor y respeto por la Madre Patria y sus formas estéticas esenciales. Asimismo ocurre con la fecha elegida para dar inicio a su historia de la literatura (1538), fecha que no representa únicamente la fundación de Bogotá, sino la conquista de Andalucía que, según Vergara, unió la patria española bajo el corazón católico. De esta manera, los motivos elegidos por el historiador apuntan siempre a unificar, a través de la ejemplificación, la historia de la Península Ibérica con la americana.
} 


\section{Diana Paola Guzmán}

(...) consagrado por fin a sus estudios favoritos, lo sorprendió en medio de ellos, el grito de Independencia, y este hombre, de condición apacible y de carácter tímido, se vio enrolado en las fuerzas revolucionarias y llegó a ser Coronel de ingenieros y a fabricar, con elementos rudimentarios, fusiles y cañones, que él mismo no habría podido disparar jamás (1938:75).

El círculo de metamorfosis empieza a funcionar como una suerte de reflector que arroja su luz al resto de los soldados escritores que conforman el imaginario propuesto por las obras históricas. Así, Quesada se convierte en el paradigma de identidad de estos personajes. Caldas, quien dentro de las obras analizadas le sigue en grado de importancia, va cerrando el círculo que el español dejó abierto: es letrado, con un alto sentido del deber y con un amor patriótico inspirado ya no por la Península Ibérica sino por Colombia. De esta forma, las historias literarias no sólo proponen un cambio de centro ejemplar, ${ }^{5}$ sino un cambio en la territorialidad. Podemos suponer, entonces, que los cambios en los diseños imaginarios de la territorialidad, por tanto, de la nacionalidad, implican alteraciones en los paradigmas identitarios. Los nuevos héroes habitan, ahora, tierras propias y su presencia servirá de eje para involucrar al resto de nacionales dentro del plan social colectivo. Al poner la mirada sobre los héroes colombianos, el punto cero histórico ya no se identifica con la Conquista, sino que presenta a la Independencia como nuevo escenario de partida.

El espacio de acción de los personajes de la Independencia se convierte en un verdadero momento liminal; una línea divisoria entre el "ahora” y el “después”, un verdadero “cambio en la historia”; es la situación propicia para mostrar a los hidalgos. En fin, la "hazaña” de la Independencia y sus actores se ha constituido en el parámetro para evaluar el pasado y avizorar el futuro, generando un sentimiento de continuidad histórica de la comunidad. De esta manera, la literatura se convierte en una parte importante de la tradición y de la historia nacional, generando una experiencia profunda de la communitas que fortalece los sentimientos de pertenencia y de trascendencia entre los miembros de la nación. La Independencia no es sólo una experiencia efímera sino que se constituye en una comunidad de origen y en una comunidad de destino. En palabras de Colmenares

\footnotetext{
${ }^{5}$ El concepto de "centro ejemplar” fue elaborado por Geertz (1990) cuando estudiaba la función simbólica que cumplían los gobernantes javaneses para su pueblo. Ahí, según la ideología cósmica del reino, la corte asumía el papel de paradigma microscópico que cumple la función de diseminar, mediante exhibición, la civilización: la capital es como el sol, y el reino es como su aureola. Para Vergara era fundamental "exhibir” a los héroes.
} 
El generar personajes novelados se convierte en una estrategia nemotécnica que convierte a la rememoración de los mismos en parte fundamental de la identidad colectiva (1989:110).

La identificación de los individuos con la sociedad requiere la transmisión de mapas cognitivos, que hacen posible —aunque sólo sea de forma precaria - la definición de la singularidad del grupo respecto a sus similares y la conformación de la solidaridad comunitaria. La urdimbre de las identidades nacionales puede considerarse, en esta perspectiva, un proceso de elaboración, difusión y adquisición de estereotipos sociales, de tipos ideales, que cristalizan o condensan, en estado puro, todo aquello que se considera distintivo de ese "nosotros esencial" que es la nación. La alquimia nacionalista convierte cualquier rasgo propio en virtud, el plomo en oro; el nacionalismo deviene en un espejo de Narciso donde se reflejan los modelos ideales. En palabras de Michel Billing

Un reflejo con fines didácticos que otorguen continuidad a la nación y trascendencia a sus miembros, esos modelos son permanentemente actualizados y transmitidos a las nuevas generaciones. Esos modelos reencarnan continuamente en héroes, próceres, prohombres y otros personajes, los cuales constituyen el "centro ejemplar” (1998:30).

Al convertirse en personaje-monumento y en centro ejemplar, el escritor soldado representa las raíces de la nación, en general. Muestra de ello es que nunca su figura aparece asociada a la barbarie, nunca es inhumano ni cruel, separándose tangencialmente de los conquistadores iletrados y bárbaros. Su única función es contar, a través de la escritura, la naturaleza que percibe, convirtiéndola en una suerte de locus amoenus y de una raíz que será heredada por la posteridad

Pero, no es encantador el saber que en medio de las azarosas peripecias de aquella tremenda selva, a través de las fragosas montañas de los Andes, Quesada aprovechara los escasos momentos de tregua para volver los ojos a sus nunca olvidados oficios literarios y tomara la defensa de los antiguos metros de su tierra, mal hallado con las formas métricas de reciente introducción (...) amaba la poesía, como la han amado los colombianos (Gómez Restrepo, 1938:21).

De esta manera, el escritor soldado abandona el ámbito de guerrero, para convertirse en el paradigma del ser letrado, en el héroe que ha dejado el campo de batalla para convertirse en una suerte de hidalgo. En este sentido, presentar al escritor soldado como Mesías social, político e intelectual era la 


\section{Diana Paola Guzmán}

imagen que las historias de la literatura pretendían reflejar. Engrandecer la figura para ocultar la debilidad de su visión

En los historiadores hispanoamericanos había una curiosa limitación en la elección de los rasgos heroicos. El héroe no encarnaba toda la gama de las potencialidades humanas, sino simplemente las de la voluntad (Romero, 1978:XX).

Es evidente que, al presentar a los primeros soldados escritores como amantes de las letras y, en consecuencia, de la civilización, los historiadores estarían generando una suerte de pacto social entre la figura del escritor y el devenir histórico de la nación.

Por lo tanto, la exposición de estas figuras era la presentación de todo un sistema colectivo tradicional. Cualquier punto de divergencia constituía una amenaza para todo un discurso histórico y estético. El estandarte de la herencia de los principios fundacionales era definido a través de la literatura que reflejaba aquellas estructuras originarias de la sociedad

Pero todos estarán en estado de permanente alerta frente a las amenazas que pudieran cernirse sobre las estructuras y sus fundamentos, a través de los cambios que, aún incipientes, delataran sus posibles proyecciones radicales (1867:X).

De esta manera, el licenciado Jiménez de Quesada regresa a las letras cuando termina su misión de hombre de guerra y de conquistador. Sin embargo, su influjo se verá reflejado en el nuevo modelo de escritor soldado que configura la propia dinámica social: el prócer de la independencia.

\section{EL ESCRITOR-PRÓCER: UN NARRADOR ILUSTRADO}

El optimismo que acompañara a la lucha de independencia en la América hispana se convertiría pronto en una realidad que no superaba las aspiraciones independentistas de los americanos. España no había desaparecido del ideario ni de su imaginario. Por el contrario, parecía estar arraigada al ser hispanoamericano. En palabras de José Carlos Chiaramonte

A la independencia política de Hispanoamérica no había seguido el mundo que la nueva filosofía prometía a todo hombre por el simple hecho de ser hombre. Fuera del cambio político, todo continuaba igual. Un señor había sustituido a otro señor. Los pueblos hispanoamericanos no habían alcanzado su libertad, sólo habían cambiado de amo. La revolución de independencia había mostrado la incapacidad de estos pueblos para la libertad. No todos los hombres tenían derecho a la 
libertad por el simple hecho de ser hombres. Había hombres que nacían con este derecho y hombres que nacían sin él, incapacitados (2004:28).

Todas las promesas que habían quedado sin cumplir demuestran que las batallas parecían espectros cuyo único legado era la muerte de miles de nacionales. Era hora de buscar, nuevamente, el narrador ideal de una historia que debía ser apropiada y amada por el pueblo naciente. Dicha misión la asumieron las historias de la literatura. En términos de Gómez Restrepo

La grande epopeya de la Independencia colombiana produjo tan eminentes escritores, tribunos, hombres de Estado como heroicos soldados; por entre tantos patriotas ilustres de esa gloriosa época, en que la grandeza de los caracteres armonizó con la del teatro y la de los acontecimientos, principios e intereses que estuvieron en acción, poco se mostraron, desde que la primera Colombia se constituyó, tan notables por su audacia y valentía civil como el doctor Azuero. A su laboriosidad debemos principalmente el Código Penal de la República, expedido desde 1837, que luego ha subsistido en la Unión y servido de modelo al Código Penal de cada uno de los Estados (1938:155).

Se hacía necesario proponer una narración de la Historia, cuyo narrador fuera, por sí solo, garantía de veracidad. Los próceres y sus testimonios de presencialidad antes, durante y después de la batalla, resultaban la mejor forma de generar credibilidad en una nación que había perdido la fe en las promesas hechas por la clase criolla. Ese colectivo descreído constituía un público mucho más difícil de convencer y que, luego de la Independencia, quería participar más activamente de los procesos que traía consigo la ruptura con España. La presencia del prócer escritor como narrador testigo y letrado marca el inicio de una nueva relación con el público lector y, por tanto, una nueva dinámica de la historia literaria ${ }^{6}$

Requiere, al menos, participar en el circuito de la comunicación lingüística, recusando el hermetismo de la palabra y de algún modo muy dentro del canon costumbrista propone el cambio y la corrección de los usos sociales que afean o disturban la vida de las repúblicas nacientes (1994:13).

\footnotetext{
${ }^{6}$ Para Antonio Cornejo Polar (1994), esta "ruptura comunicativa” entre el escritor y el lector colonial se ejemplifica en la literatura barroca y en los sermones dichos en latín. No fue sino hasta la llegada de los próceres que se comenzó a establecer una mayor comunicabilidad entre el lector y los testimonios. Posteriormente, dicho modelo se consolidaría con el costumbrismo.
} 


\section{Diana Paola Guzmán}

Como lo explica Cornejo Polar, la presencia de este nuevo narrador que parte de la acción a la reflexión configura y reafirma el carácter didáctico de la literatura y, por ende, de las historias y, a su vez, involucra al lector que debe sentirse parte de lo que lee para ser aleccionado. La primera estrategia empleada por Gómez Restrepo y que primaría en algunas de las historias subsiguientes, ${ }^{7}$ es la del orden divino que caracterizaría, además, el pensamiento conservador: todas las acciones y los procesos históricos estarían guiados por la fuerza trascendente de Dios quien, al bendecirlos, justificaría cualquier acción que devenga de esta misión providencial

Sumida la Madre Patria en la anarquía, las colonias tenían que organizarse por sí solas. La independencia se realizó en cumplimiento de las leyes naturales. Por designio providencial, aquellos sucesos ocurrieron cuando la América toda había producido una legión de hombres ilustres, cuya misión parecía fijada de antemano, pues de la tranquilidad de la Colonia surgieron armados de todas armas y listos para cumplir la misión elevada de crear nuevos Estados (1938:51. Tomo IV).

España, invadida por Napoleón, estaba sumida en un estado de caos que - según Gómez Restrepo- provocaría la Independencia que se desarrollaría a manos de próceres bendecidos por Dios. En este sentido, encontramos la siguiente característica del prócer escritor: es visto como el hombre del futuro.

No olvidemos que, ya desde Quesada, la civilización era una de sus banderas, pero jamás podría desvincularse del ser piadoso y, en esencia, conservador, pues resultaría contradictorio dentro del proceso de modernización que representaba esta figura. Por tanto, se presenta un soldado escritor que construye las bases de una nación nacida sobre el terreno del deber y de las letras que, posteriormente, con la Independencia, representaría un proceso tímido de modernidad y de modernización. Según Antonio Cornejo Polar

Como es claro, parte de esa tarea [la modernidad] tenía que hacerse discursivamente; esto es, generando sentidos socializados que permitieran forjar imágenes de pertenencia y solidaridad nacionales (1994:15).

La figura oscilante del prócer escritor parte, primero, del cumplimiento del deber, de los actos performativos, para luego convertirse en un hombre de

\footnotetext{
${ }^{7}$ Las historias de corte didáctico son, tal vez, las que mayor influencia reciben de las nacionales. Los ejemplos más claros son Resumen histórico-crítico de literatura colombiana (1952) de Jesús María Ruano. Bogotá: Ed. Santafé, y Literatura colombiana: sinopsis y comentarios de autores representativos (1952) de José Arístides Núñez Segura. Medellín: Ed. Bedout.
} 
leyes cuya responsabilidad es la cohesión y el orden social, para posteriormente, a través de su nueva metamorfosis, convertirse en la voz legítima de la historia solidaria y nacional. Por otro lado, el prócer devoto sigue vinculándose con un ámbito que reñiría con la modernidad, según la cual, el proceso de desacralización representa el surgimiento de un movimiento social que depende del hombre. El héroe sigue levantando sus ojos al cielo mientras trae la libertad, con las armas, y la República, con las letras. ${ }^{8}$

\section{EL PRÓCER ESCRITOR: FORMADOR DE LA OPINIÓN PÚBLICA}

Las historias de la literatura se convirtieron en el vehículo inicial para transportar a estas oscilantes figuras. Francisco José de Caldas — presentado por Vergara y Vergara - trae consigo la antorcha de la ciencia y la libertad.

Antonio Gómez Restrepo le dedica más páginas y reafirma la naturaleza ambivalente del escritor soldado. El capítulo dedicado a Caldas está compuesto, en su mayoría, por testimonios de Caldas sobre el sabio Mutis y el juicio que daría Humboldt sobre la noble y joven figura del científico. ${ }^{9}$ Gómez Restrepo elige los apartes más dramáticos y humanos de la narración del prócer

Mutis, celoso amante de las ciencias, abre sus tesoros. Humboldt, amante de un desembarazo pueril, oprime mi modesto equipaje, le parece complicado el aparato de una persona más. Mutis se pone en movimiento, escribe, empeña su respeto por ilustrarme. Humboldt sacrifica mi fortuna, mi gloria, por una comodidad imaginaria. Mutis, amante de su especie, quiere prolongar sus beneficios más allá de la muerte reproduciendo sus conocimientos, en jóvenes aplicados. Humboldt me deja con tranquilidad en medio de mis cadenas (1938:IV).

A lo largo del apartado dedicado a Caldas, las referencias a la superioridad ética del católico Mutis sobre Humboldt van construyendo una imagen de la naciente ciencia, que no puede ni debe desprenderse de la Iglesia, como tampoco ninguna cara de la historia que recién se conforma.

\footnotetext{
${ }^{8}$ Teóricos europeos como Jürgen Habermas y latinoamericanos como Antonio Cornejo Polar y Ángel Rama coinciden en que uno de los procesos más característicos de la modernidad es la desacralización del mundo, resultado de un orden socialmente producido, al margen de cualquier designio, como el divino. El proceso de desecularización en las naciones jóvenes es un proceso que tarda más tiempo que en otras geografías.

${ }^{9}$ Sabido es que el viaje de Caldas junto a Humboldt resulta más corto de lo esperado por el colombiano. Al parecer la diferencia de personalidades entre las dos figuras, uno "fulgurante” y Caldas "silencioso y taciturno", como lo explica él mismo, generó una ruptura que cambió los planes del joven científico.
} 


\section{Diana Paola Guzmán}

Esta presencia constante del prócer como testigo, constructor y narrador de la historia se relaciona, como ya se ha enunciado, con un lector que desea participar más activamente de los procesos que antes permanecían lejos de su conocimiento. La prensa se convierte en el escenario propicio, cuya construcción retórica y discursiva se caracteriza por ser breve e instalarse sobre lo referencial cotidiano (sus propias vivencias). De esta forma, genera la conformación de una opinión pública que construya una visión de la Independencia efectiva para un plan identitario de nación. ${ }^{10}$ En este sentido, la formación de la opinión pública debía beneficiar, en primera instancia, a un plan político y, en segundo lugar, formar —a través de la narración del relato en primera persona- - al ciudadano ideal habitante de la nación ideal. Según Cornejo Polar

La posibilidad de convencer al lector de la legitimidad de la propuesta que el texto encarna sin mayores disimulos, todo bajo la suposición —claro está - de que su objetivo final no es otro que el progreso de la nación, y la presentación de un territorio social e histórico ideal (1994:14).

Por otra parte, la misión de ser formador de la opinión pública incluía, necesariamente, la función de ser una voz colectiva y la expresión de puntos de vista que han sido socializados. De esta manera, el prócer escritor presentado en las historias de la literatura siempre orientará sus relatos a la consecución del bien común. Asume como representante y portavoz de la nación y, al mismo tiempo, hacedor y movilizador de los imaginarios en torno a la historia nacional. Este papel trae consigo otra parte del círculo de metamorfosis del prócer escritor. Construir una idea de lo propio desde dos escenarios constantes: el geográfico (constructor del tópico de abundancia) ${ }^{11} \mathrm{y}$ el del orden social y legislativo (el hombre de leyes). El representante de mayor importancia en la construcción del tópico de la abundancia es Caldas quien, por su condición de viajero y científico, tiene la autoridad de describir con voz propia el territorio colombiano, según reproduce Gómez Restrepo

La vegetación de nuestros Andes parece que toca los extremos. En el corto espacio de 20 leguas halla el botánico observador plantas análogas

\footnotetext{
${ }^{10}$ Para Pablo Macera (2002), el esplendor de la relación entre literatura y prensa se lleva a cabo en el costumbrismo donde, según el autor, el escritor de la prensa se centraba en sus propias vivencias y recalcaba, como el prócer escritor, su naturaleza de testigo y constructor.

${ }^{11}$ La construcción del tópico de abundancia se remonta a la percepción y a la representación del Nuevo Mundo como fuente de lo nuevo pero, también, como producto de la mezcla. Para una imagen de América que se forja en ese cotejo entre versiones dominantes y contraversiones nativas, Cfr. Julio Ortega. El discurso de la abundancia (2004).
} 
a las de Siberia, plantas semejantes a las de los Alpes, la vegetación de Bengala y la de la Tartaria Septentrional (...) Los bálsamos, las resinas, los aromas, los venenos, los antídotos, todas las cualidades enérgicas están en la base de nuestra soberbia cordillera (1938:95). ${ }^{12}$

Ambos paradigmas, tanto el que construye el tópico de la abundancia como el del hombre de leyes, tienen un mismo objetivo: crear sobre el mapa borroso de la historia, la geografía propia; el cuerpo de una nación que sigue pareciendo invisible para quienes no figuraron como héroes o intelectuales en la centuria del XIX. Describir un espacio lleno de universalidad, como lo hace Caldas, legitima a la nación frente a los ojos del mundo y genera una relación irrompible entre naturaleza y cultura, civilización y barbarie. De este modo, el constructor del tópico de la abundancia y el hombre de leyes son, en realidad, cartógrafos que tratan de unificar una diversidad que resultó, al final, su misión indefinible. En opinión de Graciela Montaldo

En el comienzo de la literatura latinoamericana independiente pareciera que una reflexión sobre el espacio se impone, en una doble dirección. La primera dirección focaliza el problema de escribir la patria y el estado -el momento de constitución del Estado- en sociedades que desarrollan en general y viven la guerra de los caudillos, los bárbaros, los nómadas. Es decir, se incorporó la segunda dimensión, en un espacio que también es real y relativamente desconocido, resistente a la ley, que la escritura debe cartografiar para ubicar la acción política (1994:104).

En este sentido, la acción de cartografiar desde el constructor del tópico de la abundancia y del hombre de leyes resulta en una acción complementaria en donde el primero debe visibilizar el espacio que el segundo legitimara desde la ley y desde la letra.

El hombre de leyes, por su parte, sabe combinar la valentía guerrera con la virtud de ser letrado y piadoso. Camilo Torres parece ser el representante más ponderado por Gómez Restrepo quien encuentra reflejadas en él las características del prócer escritor enunciadas anteriormente: un amplio sentido del deber, un profundo amor por la nación y por la libertad y, lo más

\footnotetext{
${ }^{12}$ Conviene aclarar que no se trata de generar un sentimiento de identidad que sea autónomo a España y que, además, proponga una mirada detenida desde lo propio. Basta con ver que, más adelante, el mismo Gómez Restrepo rescatará la importancia de Caldas como escritor, destacando la pureza de su estilo desde la influencia directa de pensadores españoles como Gaspar Melchor de Jovellanos.
} 


\section{Diana Paola Guzmán}

importante, una mente letrada que permite legitimar parte de la historia colombiana narrada en el Memorial de Agravios $^{13}$

Donoso estilo el del Memorial, franco y pulido al mismo tiempo; no obra de militar, sino de fino ideólogo. Es frecuente en la literatura colombiana hallar hombres como Torres, de vida agitada en lides militares y políticas, y al mismo tiempo pausados en las tareas intelectuales, cuidadosos de la forma literaria y del gesto humano en sus actuaciones sociales. La verdad es que habiendo sido gran literato el caudillo de América hispana, Simón Bolívar (v.), y habiendo encauzado sus buenas condiciones para las letras hacia los documentos políticos, fácilmente se explica el interés de los próceres colombianos que lo acompañaron, de dejar por escrito su pensamiento acerca de la naciente república (1938:100).

A través de esta descripción se suma otro elemento importante a la función que cumple el prócer escritor dentro del plan identitario de nación y que se relaciona, además, con la misión de formar una opinión pública: ser vigías y constructores de la memoria pública, la que se conforma por la voz de la historia oficial, respaldada por la acción ética y por la presencialidad del héroe-narrador. En palabras de Hugo Achugar: "La memoria pública es el campo de batalla en el que dos tipos de memoria (la oficial y la popular) compiten por la hegemonía” (1994:18). Es decir, el prócer escritor pasa a formar parte de los imaginarios populares, en el momento cuando la memoria oficial (historias de la literatura, periódicos literarios, etc.) ha estructurado el modo de aprehensión de la figura determinada. Como explica Javier Sasso (1994), al insertarse el prócer escritor en la memoria del pueblo, podría convertirse, con mayor efecto, en una suerte de publicista que tendría en sus manos fórmulas que permitirán la puesta en marcha de las instituciones políticas resultantes luego de la Emancipación.

Cimentar la tradición sobre la base de la Independencia convirtió al prócer escritor en productor de una literatura de ideas que centraba su atención en los hechos y reafirmaba, al mismo tiempo, la necesidad de convertir la ruptura de 1810 en un punto cero de la historia nacional. Dentro de la conformación de ese nuevo horizonte histórico, se hacía necesario

\footnotetext{
${ }^{13}$ Escrito a fines de 1809, cuando era más incierta la situación política en Europa, y dado a la luz pública un año antes de los sucesos del 20 de julio en Santafé, el Memorial circuló activamente en copias por la capital del país y vino a ser uno de los elementos determinantes en el desarrollo del grito de independencia del Nuevo Reino de Granada. La edición más completa del Memoria de agravios es la publicada en Bogotá por Fundación Nacional Epígrafe en 1986.
} 
generar, a través de la escritura, un espacio ${ }^{14}$ que contuviera el reconocimiento de una nueva geografía que debía volver a ser vista, e instaurada, a través de las leyes y la escritura. Como lo explica Michel de Certau (1988), el espacio -en este caso físico- es más bien una construcción discursiva donde se encuentran procesos de legitimación social e histórica, y se conforma el cuerpo de la nación. Por ende, el prócer escritor reparte las funciones de dicha construcción: por un lado es cartógrafo y, por otro, es la voz de la civilización a través de las leyes y la cohesión social.

\section{UN PRINCIPIO DE FORMACIÓN: EL INTELECTUAL COLOMBIANO. PRINCIPIOS DE DISCUSIÓN}

Se vislumbra, ya, lo que será el último paso dentro del círculo de metamorfosis: de escritor a soldado, de soldado a prócer escritor (en donde es cartógrafo y legalista), periodo que finalmente decantará en la figura del prócer escritor como paradigma del intelectual colombiano. Vale la pena destacar, para futuros trabajos y discusiones, problemáticas como la definición del intelectual (pensador, escritor, filósofo, humanista, letrado, cientista social, entre sus múltiples nominaciones), la pregunta por el "lugar" de las ideas y la relación entre intelectuales y procesos políticos. El prócer escritor es, de una u otra forma, el primer ápice de pensadores profundamente activos que asumirían la función de contar la historia desde su propia presencialidad.

Dentro de este panorama, sería imposible no tener en cuenta la propuesta que hace Ángel Rama en La Ciudad Letrada (1984). Rama distingue un primer momento cuando los intelectuales cumplieron una función administrativa, ligada al poder. Luego de la modernización, de fines del siglo XIX, los intelectuales adquieren mayor autonomía, lo que va de la mano con el auge de las profesiones liberales. Sin embargo, las funciones administrativas se combinaron con el inicio de una función ideologizante, de conducción espiritual de la sociedad, que sería el punto de partida de lo que Rama llama el fin de la torre de marfil, y que tendría lugar en los inicios del siglo $\mathrm{XX}^{15}$

\footnotetext{
${ }^{14}$ De Certau diferencia el concepto de lugar del concepto de espacio. "El espacio se compone de intersecciones de elementos móviles. Es actuado por el conjunto de elementos desplegados dentro de él. El espacio ocurre como el efecto producido por las operaciones que lo orientan, lo sitúan, lo temporalizan y lo hacen función de una unidad polivalente de programas conflictuales o proximidades contractuales”. Hetelogies. Discourse on the other (1988:117).

15 Según Ángel Rama, el proceso de especialización de los intelectuales en el siglo XX consolida su autonomía, lo que les permite participar en política en virtud de su alto espíritu crítico, derribando, de paso, la mítica y falsa — para Rama - imagen del escritor en su torre de
} 


\section{Diana Paola Guzmán}

En suma, el prócer escritor se constituirá como base de la idea del intelectual en el siglo XX. Las historias de la literatura colombiana lo presentan como una suerte de hombre del futuro, de raza visionaria que continúa con las manos cruzadas para la oración. De esta manera, la función de presentar la Independencia como fruto de mentes civilizadas, letradas y desarrolladas - y como punto de partida para un nuevo tiempo- abre paso a la construcción de una sociedad crítica que exige la especialización y profesionalización de los intelectuales. Al abrir la puerta al siglo XX, las historias de la literatura, a través de la presentación del escritor soldado y de su círculo de metamorfosis, van generando la imagen y la necesidad de pensadores que se involucren en un proceso de crítica, creación y guía a una nación que sigue reinventándose desde sí misma.

Universidad Santo Tomás*
Facultad de Filosofía y Letras
Unidad de Investigación y posgrados
Cra. $7 N^{\circ} 26$ A-13, Bogotá (Colombia)
Residencia: Calle 20 No 1-26, Apto. 115 Barrio Las Aguas, Bogotá
dianamayeutica@gmail.com

\section{BIBLIOGRAFÍA}

ACHUGAR, Hugo. "El Parnaso es la Nación o reflexiones a propósito de la violencia de la lectura y el simulacro", en Esplendores y miserias del siglo XIX. Cultura y sociedad en América Latina. Caracas: Monte Ávila, 1994.

BILLING, Michel. "El nacionalismo banal y la reproducción de la identidad nacional”, en Revista Mexicana de Sociología 1/98, 1998.

BRUNNER, José Joaquín y Flisfisch, Ángel. Los intelectuales y las instituciones de la cultura. Santiago de Chile: FLACSO, 1983.

CHIARAMONTE, José Carlos. Nación y Estado en Iberoamérica. El lenguaje político en tiempos de la Independencia. Buenos Aires: Sudamericana, 2004.

COLMENARES, Germán. Las convenciones contra la cultura. Cali: Universidad del Valle Editores, 1989.

marfil. Más tarde, las naciones de América Latina verán imponerse nacionalismos, populismos y democracias autoritarias. En este escenario, los intelectuales se incorporan a los partidos políticos y, paralelamente, aprovechan la aparición de un público lector masivo que les otorga cierto poder distintivo. Lamentablemente, la muerte sorprendió a Rama impidiendo que puliese y finalizase este libro siendo, justamente, las últimas décadas las menos elaboradas. 
CORNEJO POLAR, Antonio. "La Literatura Hispanoamericana del siglo XIX: Continuidad y Ruptura (Hipótesis a partir del caso Andino)”, en Esplendores y miserias del siglo XIX. Cultura y sociedad en América Latina. Caracas: Monte Ávila, 1994.

DE CERTAU, Michel. Hetelogies. Discourse on the other. Minneapolis: University of Minnesota Press, 1988.

DELEUZE, Gilles. Lógica del sentido. Barcelona: Barral, 1971.

GEERTZ, Clifford. La interpretación de las culturas. Buenos Aires: Gedisa, 1990.

GODOY URZÚA, Hernán. El oficio de las letras. Estudio sociológico de la vida literaria. Santiago de Chile: Universitaria, 1970.

GÓMEZ RESTREPO, Antonio. Historia de la literatura colombiana. Bogotá: Imprenta Nacional, 4 Vols., 1938.

MACERA, Pablo. "Pensar la Historia Latinoamericana desde Los Andes”, en Araucaria, Revista Iberoamericana de filosofía, política y humanidades, 7, 2002.

MONTALDO, Graciela. "El cuerpo de la patria: espacio, naturaleza y cultura en Bello y Sarmiento", en Esplendores y miserias del siglo XIX. Cultura y sociedad en América Latina. Caracas: Monte Ávila, 1994.

NÚÑEZ SEGURA, José Arístides. Literatura colombiana: sinopsis y comentarios de autores representativos. Medellín: Bedault, 1952.

ORTEGA, Julio. El discurso de la abundancia. Caracas: Monte Ávila, 2004.

PIZARRO, Ana. Palabra, literatura e cultura (volumen 2: Emancipación do discurso). São Paulo: Memoria, 1994.

RAMA, Ángel. La ciudad letrada. Hannover: Ediciones del Norte, 1984.

RAMA, Carlos M. (Ed.) Los intelectuales y la política. Montevideo: Nuestro Tiempo, 1962.

RICOEUR, Paul. Tiempo y Narración. Barcelona: Siglo XXI, 1998.

------- Historia y narratividad. Introducción de Ángel Gabilondo y Gabriel Aranzueque. Barcelona: Paidós, ICE de la Universidad Autónoma de Barcelona, 1999.

ROMERO, José Luis. Pensamiento conservador (1815-1898). Caracas: Biblioteca Ayacucho, 1978.

ROSALDO, Renato. Cultura y Verdad. Nueva propuesta de análisis social. México: CNCA-Grijalbo, 1991.

RUANO, Jesús María. Resumen histórico-crítico de literatura colombiana. Bogotá: Santa Fe, 1952.

SASSO, Javier. "Romanticismo y política en América Latina: una reconsideración”, en Esplendores y miserias del siglo XIX. Cultura y sociedad en América Latina. Caracas: Monte Ávila, 1994. 


\section{Diana Paola Guzmán}

SAMPER, José María. Ensayo sobre las revoluciones políticas y la condición social de las Repúblicas colombianas (hispano-americanas): con un apéndice sobre la orografía y la población de la Confederación Granadina. Bogotá: Biblioteca Popular de Cultura Colombiana, 1861.

SANTANA, Joaquín. El problema de la modernidad en América Latina; una aproximación histórico-sociológica a la contradicción civilización/barbarie. México: UNAM, 2005.

TORRES, Camilo. Memorial de agravios. Bogotá: Fundación Nacional de Epígrafe, 1986.

VERGARA Y VERGARA, José María. Historia de la literatura en Nueva Granada. Bogotá: Echeverría Hermanos, 1867. 